\title{
Article \\ Indoor Air Quality: Assessment of Dangerous Substances in Incense Products
}

\author{
Gabriela Ventura Silva ${ }^{1, *}$, Anabela O. Martins ${ }^{1}$ (D) and Susana D. S. Martins ${ }^{2}$ \\ 1 INEGI-LAETA, Institute of Science and Innovation in Mechanical and Industrial Engineering (INEGI)- \\ Associated Laboratory for Energy and Aeronautics (LAETA), R. Dr. Roberto Frias, 400, \\ 4200-465 Porto, Portugal; amartins@inegi.up.pt \\ 2 INEGI, Institute of Science and Innovation in Mechanical and Industrial Engineering, \\ R. Dr. Roberto Frias, 400, 4200-465 Porto, Portugal; smartins@inegi.up.pt \\ * Correspondence: gventura@inegi.up.pt
}

Citation: Silva, G.V.; Martins, A.O. Martins, S.D.S. Indoor Air Quality: Assessment of Dangerous Substances in Incense Products. Int. J. Environ. Res. Public Health 2021, 18, 8086. https://doi.org/10.3390/ ijerph18158086

Academic Editor: Paul B. Tchounwou

Received: 3 May 2021

Accepted: 28 July 2021

Published: 30 July 2021

Publisher's Note: MDPI stays neutra with regard to jurisdictional claims in published maps and institutional affiliations.

Copyright: (c) 2021 by the authors. Licensee MDPI, Basel, Switzerland. This article is an open access article distributed under the terms and conditions of the Creative Commons Attribution (CC BY) license (https:/ / creativecommons.org/licenses/by/ $4.0 /)$.
Abstract: Indoor air pollution has obtained more attention in a moment where "stay at home" is a maximum repeated for the entire world. It is urgent to know the sources of pollutants indoors, to improve the indoor air quality. This study presents some results obtained for twelve incense products, used indoors, at home, and in temples, but also in spa centers or yoga gymnasiums, where the respiratory intensity is high, and the consequences on health could be more severe. The focus of this study was the gaseous emissions of different types of incense, performing a VOC screening and identifying some specific VOCs different from the usual ones, which are known or suspected to cause severe chronic health effects: carcinogenic, mutagenic, and reprotoxic. Thirteen compounds were selected: benzene, toluene, styrene, naphthalene, furfural, furan, isoprene, 2-butenal, phenol, 2-furyl methyl ketone, formaldehyde, acetaldehyde, and acrolein. The study also indicated that incense cone type shows a higher probability of being more pollutant than incense stick type, as from the 12 products tested, four were cone type, and three of them were in the group of the four higher polluters. Benzene and formaldehyde presented worrying levels in the major part of the products, above guideline values established by the WHO. Unfortunately, there are no limit values established for indoor air for all the compounds studied, but this fact should not exempt us from taking action to alert the population to the potential dangers of using those products. From this study, acetaldehyde, acrolein, furfural, and furan emerge as compounds with levels to deserve attention.

Keywords: indoor air quality; VOC; incense; carcinogenic; mutagenic and reprotoxic compounds

\section{Introduction}

It is now well established that indoor air pollution contributes significantly to the global burden of disease in the population [1]. In the presence of indoor sources, indoor contaminant concentrations are higher, sometimes 10 times higher (e.g., VOCs) than the respective outdoor air levels, regardless of the building location. Moreover, if until recently people spent about $90 \%$ of their time in confined spaces, distributed by the workplace, means of transport, home or leisure spaces, today, for a ratio of the population, that time reaches $99 \%$ or even $100 \%$ in the case of sick people at home or students and workers teleworking. Indoor Air Quality (IAQ) has thus become an even more relevant concern, since prolonged exposure to the same profile of potentially toxic substances, even at low concentrations, may affect human health, causing or aggravating diseases such as allergies, nose and skin irritation, asthma, and other airborne respiratory infections, chronic obstructive pulmonary disease, lung cancer, and cardiovascular disease.

Acting to improve IAQ in any space requires understanding the occupants and the dynamics of the spaces. One of the main parameters is, without doubt, the sources that can be so diverse as construction materials [2,3], furniture and decoration materials [4], consumer products [5,6], air conditioning systems [7], the occupants themselves and their 
activities [8-10]. In the last decades, regulatory efforts have improved, and many chemical compounds have been subjected to restrictions. Nevertheless, many other compounds appeared to replace the restricted ones.

This article presents some results obtained for incense, a product used indoors, at home, and temples, but also in spa centers or yoga gymnasiums, as some persons believe that incense emit favorable fragrances that can relieve stress and facilitate the attainment of physical, mental, and spiritual balance [11].

Previous studies show that incense burning emits many particles [12-15], and some studies present the chemical characterization of the particulate phase $[11,16,17]$. The results show high emissions levels, which demonstrate that the use of those products without adequate ventilation represents a risk for health.

In a study presented by Ho and Yu [18], a high concentration level of formaldehyde and acrolein was detected in indoor environments (temples and homes) where incense is burning, exceeding the World Health Organization (WHO) air quality guideline [1] of $100 \mu \mathrm{g} / \mathrm{m}^{3}$ for formaldehyde. Other aldehydes like acetaldehyde, benzaldehyde, furfural, glyoxal, and methylglyoxal were also identified.

Lee and Wang [13] studied 10 types of incense and found that benzene, toluene, methyl chloride, and methylene chloride concentrations increased significantly during the burning of the products. They also measured the concentration after burning and found that for some VOCs, the concentrations were even higher after burning than during burning, which implies that the human exposure period may be lengthy.

In 2008 a review article published by Lin et al. [19] revealed that when incense smoke pollutants are inhaled, they cause airway dysfunction and advise that incense smoke is a risk factor for elevated cord blood IgE levels. It has also been indicated to cause allergic contact dermatitis, and it has been associated with neoplasm.

In the study conducted by $\mathrm{He}$ et al. [20], they found that pregnant women who frequently smelled the incense burning at late pregnancy had an associated higher risk of hypertensive disorders and higher blood pressure levels. Wei et al. [21] found an association between household incense burning and delay in infant gross motor development.

Incense products are also used as mosquito repellents, being a way to repel insects during summer overnight in households across the world. In the study performed by $\mathrm{Lu}$ et al. [22], about 230 compounds divided by 14 classes of VOCs were found in the smoke of mosquito-repellent incense. The number and content of alkanes were the highest, followed by aromatic hydrocarbons and esters. In 2018, Wang et al. [23] had already carried out a study on mosquito repellent incenses and found that formaldehyde was the major component, accounting for 10 to $20 \%$ of the total amount of pollutants.

The focus of the present study was the gaseous emissions of different types of incense, performing a VOC screening, and identifying some other different than usual specific VOCs, which are known or suspected to cause severe chronic health effects: carcinogenic, mutagenic, and reprotoxic. Other compounds without classification but known to have fatal consequences were also scrutinized. From the VOC screening, several VOCs of different families were identified: aromatic hydrocarbons, alkanes, alkenes, ketones, aldehydes. Only a set of compounds causing concern, taking into consideration the ECHA (European Chemicals Agency) [24] classification, were selected for this study:

- benzene (carcinogenic and mutagenic);

- $\quad$ toluene (suspected to be reprotoxic);

- $\quad$ styrene (suspected to be reprotoxic);

- naphthalene (suspected to be carcinogenic);

- furfural (suspected to be carcinogenic);

- furan (carcinogenic, suspected to be mutagenic and SVHC);

- $\quad$ isoprene (carcinogenic and suspected to be mutagenic);

- $\quad$ formaldehyde (carcinogenic, suspected to be mutagenic and skin sensitizing);

- acetaldehyde (carcinogenic and suspected to be mutagenic);

- 2-butenal (suspected to be mutagenic); 
- $\quad$ phenol (suspected to be mutagenic);

- $\quad$ 2-furyl methyl ketone (fatal if inhaled and fatal in contact with skin); and

- $\quad$ acrolein (fatal if swallowed or inhaled).

\section{Materials and Methods}

Twelve different incense products commercialized in Europe were studied: four products were cone type, and eight were stick type. The characteristics of the products are presented in Table 1 . The values presented are the average of the measurements performed on three different samples. Mass values were obtained using a balance Kern and the dimensions using a caliper. The diameter of the cone incense is the diameter of the basis of the cone. The burning time is the burning time coincident with sampling time, adapted to the total burning time of the different products.

Table 1. Physical characteristics of the incense products.

\begin{tabular}{|c|c|c|c|c|c|c|}
\hline & \multirow{2}{*}{ Type } & \multirow{2}{*}{$\begin{array}{c}\text { Length }(\mathrm{cm}) \\
\text { Combustible Part }\end{array}$} & \multirow{2}{*}{$\begin{array}{c}\text { Diameter (mm) } \\
\text { Combustible Part }\end{array}$} & \multirow{2}{*}{$\begin{array}{l}\text { Volume } \\
\left(\mathrm{cm}^{3}\right)\end{array}$} & \multirow{2}{*}{ Weight (g) } & \multirow{2}{*}{$\begin{array}{l}\text { Burning Time } \\
\text { (min) }\end{array}$} \\
\hline & & & & & & \\
\hline Inc 1 & Cone & $3.42 \pm 0.01$ & $12.68 \pm 0.12$ & 1.44 & $1.68 \pm 0.01$ & 15 \\
\hline Inc 2 & Stick & $18.13 \pm 0.21$ & $3.12 \pm 0.02$ & 1.38 & $1.26 \pm 0.06$ & 20 \\
\hline Inc 3 & Stick & $14.87 \pm 0.25$ & $2.43 \pm 0.19$ & 0.69 & $0.77 \pm 0.04$ & 21 \\
\hline Inc 4 & Stick & $22.00 \pm 0.24$ & $2.67 \pm 0.05$ & 1.23 & $0.90 \pm 0.01$ & 20 \\
\hline Inc 5 & Stick & $13.37 \pm 0.05$ & $2.10 \pm 0.00(0)$ & 0.46 & $0.42 \pm 0.00(5)$ & 20 \\
\hline Inc 6 & Stick & $12.67 \pm 0.12$ & $3.25 \pm 0.12$ & 1.05 & $0.78 \pm 0.04$ & 20 \\
\hline Inc 7 & Stick & $15.63 \pm 0.31$ & $3.22 \pm 0.18$ & 1.27 & $1.23 \pm 0.03$ & 24 \\
\hline Inc 8 & Stick & $25.73 \pm 0.12$ & $3.97 \pm 0.05$ & 3.18 & $2.30 \pm 0.18$ & 25 \\
\hline Inc 9 & Cone & $3.19 \pm 0.04$ & $13.80 \pm 0.11$ & 1.59 & $1.30 \pm 0.05$ & 15 \\
\hline Inc 10 & Stick & $23.17 \pm 0.05$ & $3.73 \pm 0.02$ & 2.53 & $2.41 \pm 0.06$ & 25 \\
\hline Inc 11 & Cone & $3.48 \pm 0.12$ & $13.97 \pm 0.05$ & 1.78 & $1.71 \pm 0.05$ & 15 \\
\hline Inc 12 & Cone & $4.12 \pm 0.04$ & $18.03 \pm 0.13$ & 3.51 & $2.95 \pm 0.02$ & 25 \\
\hline
\end{tabular}

The test was performed in a test chamber according to ISO 16000-9 [25] and EN 16738 [26]. The test chamber, in stainless steel, had a volume of $1.0 \mathrm{~m}^{3}$ and was supplied continuously with clean air to complete two air changes per hour. The visual control of the burning behavior was performed using a webcam installed inside the chamber. The temperature, relative humidity, and oxygen levels were recorded continuously, using a Logger 175-H2 from Testo and a ToxiRAE Pro from RAE, respectively.

With the test chamber empty, VOCs and VVOCs were collected in tubes with Tenax TA and Carboxen 569. Formaldehyde, acetaldehyde, and acrolein were collected in cartridges impregnated with DNPH.

On the day of the test, five sticks/cones of the incense were chosen. Two sticks/cones were placed inside the test chamber, and three sticks/cones were kept outside the chamber in a control room as foreseen in the standard. The test started with lighting the sticks/cones (using a gas flame). After $5 \mathrm{~min}$, (equilibration time), pollutants were collected from the chamber on average for $20 \mathrm{~min}$ (between 15 and $25 \mathrm{~min}$ depending on the product), in tubes with Tenax TA/Carboxen 569 and cartridges (from Waters) filled with silica gel coated with 2,4-dinitrophenylhydrazine (DNPH). Sampling was performed using the pump Apex Casella for VOCs and AirChek XR5000, SKC for low molecular aldehydes.

For VOC and VVOC identification and quantification, based on ISO 16000-6 [27], thermal desorption in line with gas chromatography coupled to a mass spectrometer detector (GC/MSD) was used. The GC used is from Agilent Technologies, model 7890A, and the mass spectrometer detector is also from Agilent, model 5975C. The thermal desorption system is from DANI, model TD Master. In the thermal process, the samples were desorbed 
at $300{ }^{\circ} \mathrm{C}$ for $10 \mathrm{~min}$. Desorbed VVOCs and VOCs were first captured in a Tenax-TA-filled cold trap at $-25^{\circ} \mathrm{C}$, and then quickly heated to $300{ }^{\circ} \mathrm{C}$ to introduce analytes to the GC. Compounds were separated in an HP-5MS capillary column (length: $50 \mathrm{~m}$, inner diameter: $0.20 \mathrm{~mm}$, film thickness: $0.33 \mu \mathrm{m}$ ) with helium (purity $>99.9995 \%$ ) as the carrier gas. The quantification of the selected compounds was performed using the specific response factors. The standard solutions were prepared, weighing the pure compounds (analytical balance Scaltec) and diluting them with methanol. The correlation factor of the analytical calibration curve exceeded 0.99 , and the limit of detection reached $0.47 \mu \mathrm{g} / \mathrm{m}^{3}$ for toluene and $0.30 \mu \mathrm{g} / \mathrm{m}^{3}$ for benzene. With an expanded uncertainty of $4 \%$ for toluene, the analytical method was linear in the range of 10 to $5000 \mathrm{ng}$. Total volatile organic compounds concentration (TVOC) was calculated for all compounds eluted between hexane and hexadecane, using the toluene response factor.

Formaldehyde, acetaldehyde, and acrolein were determined based on ISO 16000-3 [28]. After sample collection, the cartridges were sealed and refrigerated at $4{ }^{\circ} \mathrm{C}$ until analysis. Each cartridge was extracted with $5 \mathrm{~mL}$ of acetonitrile. The extracted solutions were analyzed by high-performance liquid chromatography (HPLC) using a chromatograph from Agilent Technologies, model 1220 Infinity LC. The column was a Reversed-Phase C18 (Zorbax ODS, $25 \mathrm{~cm} \times 4.6 \mathrm{~mm}, 5 \mu \mathrm{m}$ ). The emission factor of the compounds was calculated based on the specific response factor of the analytical method. The standard solutions were prepared using the pure derivatized compounds with DNPH, through weight (analytical balance Scaltec), and dilution with acetonitrile. The correlation factor of the analytical calibration curve exceeded 0.99 , and the average limit of detection reached $0.0046 \mu \mathrm{g} / \mathrm{mL}$.

\subsection{Reagents}

The solvent used for VOCs standard solutions was methanol (Fisher Chemical, Loughborough, UK, 99.99\%), and the highest quality possible of pure compounds were used: benzene (Sigma-Aldrich, MO, USA, >99.9\%), toluene (Sigma-Aldrich, WI, USA, 99.5\%), styrene (Sigma-Aldrich, MO, USA >99\%), naphthalene (Sigma-Aldrich, MO, USA, 99.9\%), furfural (Fluka, Switzerland, $>99 \%$ ), furan (Aldrich, MO, USA, $\geq 99 \%$ ), isoprene (Aldrich, MO, USA, 99\%), 2-butenal (Aldrich, MO, USA $\geq 99.5 \%$ ), phenol (Sigma-Aldrich, Switzerland, 99\%), 2-furyl methyl ketone (Aldrich, MO, USA, 99\%). The solvent used for aldehydes with low molecular weight solutions was acetonitrile (Sigma-Aldrich, MO, USA, 99.9\%), and the derivatives compounds of 2,4-DNPH were: formaldehyde-2,4-DNPH (Supelco, PA, USA, 99.9\%), acetaldehyde-2,4-DNPH (Supelco, PA, USA, 99.9\%), and acrolein-2,4-DNPH (solution in acetonitrile, Aldrich, PA, USA, 99.9\%).

\subsection{Evaluation of the Results}

The assessment of the test results from the emissions was performed according to EN 16739 [29]. The personal exposure levels were calculated through short-term peak concentration (STPC) and worst-case time-weighted average (TWA) and compared with relevant published indoor air limits for benzene, naphthalene, formaldehyde, toluene, and styrene. The STPC value $\left(\mu \mathrm{g} / \mathrm{m}^{3}\right)$ over the measurement period is given by the formula:

$$
S T P C=\frac{S E R}{[R V * V R]}
$$

The TWA value is calculated according to the formula:

$$
T W A=\frac{S E R}{[R V * V R]} * A U F
$$

where:

$S E R$-specific emission rate $(\mu \mathrm{g} / \mathrm{h})$

$R V$ 一room volume $\left(\mathrm{m}^{3}\right)$, assumed as $30 \mathrm{~m}^{3}$ 
$V R$-ventilation rate $\left(\mathrm{h}^{-1}\right)$, assumed as $0.5 \mathrm{~h}^{-1}$

AUF (Average Use Factor)-(Exposure time h per day $/ 24(\mathrm{~h})) \times$ (Frequency of use (day)/7 (day)), being assumed the frequency of use 4 days per week and exposure time $1 \mathrm{~h}$ per day.

EN 16739 [29] assumes the frequency of use 4 days per week and exposure time $4 \mathrm{~h}$ per day in the case of candles. Considering incense is not used so much, it was considered only $1 \mathrm{~h}$ per day in the calculations of TWA.

The limit values established by the WHO for indoor air are presented in Table 2. To note that as benzene is a genotoxic carcinogen in humans, the WHO cannot recommend a safe level of exposure. Considering that the geometric mean of the range of the estimates of the excess lifetime risk of leukemia at a benzene air concentration of $1 \mu \mathrm{g} / \mathrm{m}^{3}$ is $6 \times 10^{-6}$, the concentrations of airborne benzene associated with an excess lifetime risk of $1 / 1,000,000$ is $0.17 \mu \mathrm{g} / \mathrm{m}^{3}$.

Table 2. Guideline values for individual substances [1,30].

\begin{tabular}{ccc}
\hline Compound & $\begin{array}{c}\text { Limit Value } \\
\left(\mu \mathrm{g} / \mathbf{m}^{3}\right)\end{array}$ & Averaging Time \\
\hline benzene & 0.17 & associated with an excess lifetime risk of $1 / 1,000,000$ \\
formaldehyde & 100 & $30 \mathrm{~min}$ \\
naphthalene & 10 & 1 week \\
toluene & 260 & 1 week \\
styrene & 260 &
\end{tabular}

\section{Results}

Table 3 shows the average values of temperature, relative humidity, and oxygen in the test chamber before starting and during the test. Maximum values achieved for the parameters are presented, except in the case of oxygen, where the value presented is the minimum value reached.

Table 4 shows the average values of the emission factor of VOCs and VVOCs, selected in this study in the test chamber for the twelve products tested. Only compounds with concentrations above $2 \mu \mathrm{g} / \mathrm{m}^{3}$ are reported. Values below are stated as not detected (n.d.). Values of TVOC are also presented.

The personal exposure levels were calculated through short-term peak concentration (STPC) and worst-case time-weighted average (TWA) as defined previously, using Equations (1) and (2). Table 5 presents the STPC values, and Table 6 the TWA values obtained by calculation.

The analysis of the results obtained was performed by grouping the compounds according to their effects on human health: carcinogenicity, reprotoxicity, and mutagenicity. The focus will be on worst-case time-weighted average (TWA) values as these health effects are usually a consequence of long exposure. In the case of dangerous compounds with acute effects, the focus will be on the short-term peak concentration (STPC).

Table 3. Recorded values for Temperature, Relative Humidity and Oxygen.

\begin{tabular}{cccccccccccccc}
\hline & Inc & Inc & Inc & Inc & Inc & Inc & Inc & Inc & Inc & Inc & Inc & Inc & Average Values \\
& $\mathbf{1}$ & $\mathbf{2}$ & $\mathbf{3}$ & $\mathbf{4}$ & $\mathbf{5}$ & $\mathbf{6}$ & $\mathbf{7}$ & $\mathbf{8}$ & $\mathbf{9}$ & $\mathbf{1 0}$ & $\mathbf{1 1}$ & $\mathbf{1 2}$ & \\
\hline Temperature $\left({ }^{\circ} \mathrm{C}\right)$ & & & & & & & & & & & & & \\
\hline Initial & 24.2 & 24.0 & 24.5 & 24.0 & 24.0 & 22.9 & 23.4 & 23.3 & 22.9 & 22.9 & 24.0 & 23.5 & $23.6 \pm 0.5$ \\
\hline Final & 25.0 & 24.4 & 25.1 & 24.4 & 24.5 & 23.3 & 24.2 & 23.5 & 23.5 & 23.8 & 24.5 & 24.6 & $24.2 \pm 0.6$ \\
\hline Maximum & 25.6 & 24.5 & 25.1 & 24.5 & 24.7 & 23.4 & 24.2 & 23.6 & 24.2 & 24.0 & 25.0 & 25.3 & $24.5 \pm 0.6$ \\
\hline
\end{tabular}


Table 3. Cont.

\begin{tabular}{cccccccccccccc}
\hline & Inc & Inc & Inc & Inc & Inc & Inc & Inc & Inc & Inc & Inc & Inc & Inc \\
$\mathbf{1}$ & $\mathbf{2}$ & $\mathbf{3}$ & $\mathbf{4}$ & $\mathbf{5}$ & $\mathbf{6}$ & $\mathbf{7}$ & $\mathbf{8}$ & $\mathbf{9}$ & Average Values \\
\hline RH (\%) & & & & & & & & & & & & & \\
\hline Initial & 49.8 & 50.2 & 47.2 & 45.8 & 46.4 & 48.9 & 48.1 & 49.7 & 49.8 & 47.9 & 41.8 & 45.8 & $47.6 \pm 2.3$ \\
\hline Final & 50.2 & 50.2 & 47.1 & 46.6 & 45.9 & 49.1 & 48.2 & 49.5 & 49.7 & 47.2 & 42.0 & 45.2 & $47.6 \pm 2.3$ \\
\hline Maximum & 52.0 & 50.7 & 47.3 & 46.8 & 46.5 & 49.4 & 48.3 & 49.7 & 50.3 & 47.4 & 42.5 & 45.6 & $48.0 \pm 2.5$ \\
\hline Oxygen (\%) & & & & & & & & & & & & & \\
\hline Initial & 20.9 & 20.9 & 20.9 & 20.9 & 20.9 & 20.9 & 20.9 & 20.9 & 20.9 & 20.9 & 20.9 & 20.9 & $20.9 \pm 0.0(0)$ \\
\hline Final & 20.9 & 20.9 & 20.9 & 20.9 & 20.9 & 20.9 & 20.9 & 20.9 & 20.9 & 20.9 & 20.9 & 20.9 & $20.9 \pm 0.0(0)$ \\
\hline Minimum & 20.3 & 20.6 & 20.9 & 20.9 & 20.9 & 20.6 & 20.9 & 20.9 & 20.0 & 20.9 & 20.0 & 20.9 & $20.7 \pm 0.3$ \\
\hline
\end{tabular}

Table 4. Average emission factor $(\mu \mathrm{g} / \mathrm{h}$ ) values for TVOC, VOCs, and VVOCs selected in this study and observed in the test chamber for the twelve products tested.

\begin{tabular}{|c|c|c|c|c|c|c|c|c|c|c|c|c|c|}
\hline & CAS & Inc 1 & $\begin{array}{c}\text { Inc } \\
2\end{array}$ & $\begin{array}{c}\text { Inc } \\
3\end{array}$ & $\begin{array}{c}\text { Inc } \\
4\end{array}$ & $\begin{array}{c}\text { Inc } \\
5\end{array}$ & $\begin{array}{c}\text { Inc } \\
6\end{array}$ & $\begin{array}{c}\text { Inc } \\
7\end{array}$ & $\begin{array}{c}\text { Inc } \\
8\end{array}$ & $\begin{array}{c}\text { Inc } \\
9\end{array}$ & $\begin{array}{l}\text { Inc } \\
10\end{array}$ & $\begin{array}{l}\text { Inc } \\
11\end{array}$ & $\begin{array}{l}\text { Inc } \\
12\end{array}$ \\
\hline furan & $110-00-9$ & 4348 & 1133 & 898 & 1254 & 383 & 1924 & 1109 & 2838 & 4254 & 2653 & 3383 & 3780 \\
\hline isoprene & $78-79-5$ & 1868 & 470 & 1717 & 511 & n.d. & 889 & 497 & 1440 & 558 & 2172 & 3687 & 1752 \\
\hline (E)-2-butenal & $123-73-9$ & n.d. * & 45.9 & n.d. & n.d. & 58.1 & 34.9 & n.d. & n.d. & 53.9 & 82.5 & 69.9 & 92.1 \\
\hline benzene & $71-43-2$ & 9117 & 1412 & 1548 & 726 & 284 & 916 & 377 & 1964 & 1170 & 4180 & 1340 & 2300 \\
\hline toluene & $108-88-3$ & 2465 & 495 & 1663 & 486 & 281 & 589 & 312 & 1061 & 564 & 1081 & 1585 & 626 \\
\hline furfural & 98-01-1 & 1616 & 386 & 392 & 363 & 463 & 497 & 1199 & 860 & 634 & 748 & 932 & 1189 \\
\hline styrene & $100-42-5$ & 413 & 136 & 228 & 145 & 151 & 187 & 95.7 & 204 & 89.7 & 417 & 195 & 66.2 \\
\hline $\begin{array}{l}\text { 2-furyl methyl } \\
\text { ketone }\end{array}$ & $1192-62-7$ & 67.8 & n.d. & n.d. & n.d. & n.d. & n.d. & 56.7 & 46.7 & n.d. & n.d. & n.d. & 77.4 \\
\hline phenol & $108-95-2$ & 160 & n.d. & 33.0 & n.d. & 61.3 & 29.8 & n.d. & 77.3 & 25.4 & n.d. & n.d. & 26.1 \\
\hline naphthalene & $91-20-3$ & n.d. & n.d. & 6.01 & 3.00 & n.d. & 4.70 & 5.66 & 4.82 & 10.5 & 9.76 & 16.0 & n.d. \\
\hline formaldehyde & $50-00-0$ & 4117 & 2383 & 1845 & 3092 & 1108 & 1872 & 3091 & 3236 & 2540 & 2656 & 1350 & 3667 \\
\hline acetaldehyde & $75-07-0$ & 3634 & 1765 & 780 & 1067 & 547 & 864 & 544 & 155 & 1959 & 827 & 1731 & 139 \\
\hline acrolein & $107-02-8$ & 1581 & 927 & 658 & 920 & 235 & 608 & 421 & 817 & 707 & 807 & 601 & 284 \\
\hline TVOC & & 16310 & 4467 & 6866 & 5565 & 2433 & 3868 & 2986 & 7210 & 5115 & 9370 & 9928 & 15571 \\
\hline
\end{tabular}

Table 5. Average STPC values (short-term peak concentration) $\left(\mu \mathrm{g} / \mathrm{m}^{3}\right)$ for TVOC, VOCs, and VVOCs selected in this study in the test chamber for the twelve products tested.

\begin{tabular}{|c|c|c|c|c|c|c|c|c|c|c|c|c|c|}
\hline & CAS & $\begin{array}{c}\text { Inc } \\
1\end{array}$ & $\begin{array}{c}\text { Inc } \\
2\end{array}$ & $\begin{array}{c}\text { Inc } \\
3\end{array}$ & $\begin{array}{c}\text { Inc } \\
4\end{array}$ & $\begin{array}{c}\text { Inc } \\
5\end{array}$ & $\begin{array}{c}\text { Inc } \\
6\end{array}$ & $\begin{array}{c}\text { Inc } \\
7\end{array}$ & $\begin{array}{c}\text { Inc } \\
8\end{array}$ & $\begin{array}{c}\text { Inc } \\
9\end{array}$ & $\begin{array}{c}\text { Inc } \\
10\end{array}$ & $\begin{array}{c}\text { Inc } \\
11\end{array}$ & $\begin{array}{c}\text { Inc } \\
12\end{array}$ \\
\hline furan & $110-00-9$ & 290 & 75.6 & 59.9 & 83.6 & 25.5 & 128 & 73.9 & 189 & 284 & 177 & 226 & 252 \\
\hline isoprene & $78-79-5$ & 125 & 31.3 & 114 & 34.0 & - & 59.3 & 33.1 & 96.0 & 37.2 & 145 & 246 & 117 \\
\hline (E)-2-butenal & $123-73-9$ & - & 3.06 & - & - & 3.87 & 2.32 & - & - & 3.59 & 5.50 & 4.66 & 6.14 \\
\hline benzene & $71-43-2$ & 608 & 94.2 & 103 & 48.4 & 18.9 & 61.1 & 25.1 & 131 & 78.0 & 279 & 89.4 & 153 \\
\hline toluene & $108-88-3$ & 164 & 33.0 & 111 & 32.4 & 18.7 & 39.3 & 20.8 & 70.8 & 37.6 & 72.1 & 106 & 41.8 \\
\hline furfural & 98-01-1 & 108 & 25.7 & 26.1 & 24.2 & 30.9 & 33.1 & 79.9 & 57.3 & 42.3 & 49.9 & 62.2 & 79.3 \\
\hline styrene & $100-42-5$ & 27.6 & 9.04 & 15.2 & 9.70 & 10.1 & 12.5 & 6.38 & 13.6 & 5.98 & 27.8 & 13.0 & 4.41 \\
\hline
\end{tabular}


Table 5. Cont.

\begin{tabular}{|c|c|c|c|c|c|c|c|c|c|c|c|c|c|}
\hline & CAS & $\begin{array}{c}\text { Inc } \\
1\end{array}$ & $\begin{array}{c}\text { Inc } \\
2\end{array}$ & $\begin{array}{c}\text { Inc } \\
3\end{array}$ & $\begin{array}{c}\text { Inc } \\
4\end{array}$ & $\begin{array}{c}\text { Inc } \\
5\end{array}$ & $\begin{array}{c}\text { Inc } \\
6\end{array}$ & $\begin{array}{c}\text { Inc } \\
7\end{array}$ & $\begin{array}{c}\text { Inc } \\
8\end{array}$ & $\begin{array}{c}\text { Inc } \\
9\end{array}$ & $\begin{array}{c}\text { Inc } \\
10\end{array}$ & $\begin{array}{c}\text { Inc } \\
11\end{array}$ & $\begin{array}{c}\text { Inc } \\
12\end{array}$ \\
\hline $\begin{array}{l}\text { 2-furyl methyl } \\
\text { ketone }\end{array}$ & $1192-62-7$ & 4.52 & - & - & - & - & - & 3.78 & 3.11 & - & - & - & 5.16 \\
\hline phenol & $108-95-2$ & 10.7 & - & 2.20 & - & 4.09 & 1.98 & - & 5.15 & 1.69 & - & - & 1.74 \\
\hline naphthalene & $91-20-3$ & - & - & - & - & - & - & - & - & 0.70 & 0.65 & 1.07 & - \\
\hline formaldehyde & $50-00-0$ & 274 & 159 & 123 & 206 & 73.9 & 125 & 206 & 216 & 169 & 177 & 90.0 & 244 \\
\hline acetaldehyde & $75-07-0$ & 242 & 118 & 52.0 & 71.2 & 36.5 & 57.6 & 36.2 & 10.3 & 131 & 55.2 & 115 & 9.26 \\
\hline acrolein & $107-02-8$ & 105 & 61.8 & 43.9 & 61.4 & 15.6 & 40.6 & 28.1 & 54.5 & 47.1 & 53.8 & 40.1 & 18.9 \\
\hline TVOC & & 1087 & 298 & 458 & 371 & 162 & 258 & 199 & 481 & 341 & 625 & 662 & 1038 \\
\hline
\end{tabular}

Table 6. Average TWA values (worst-case time-weighted average) $\left(\mu \mathrm{g} / \mathrm{m}^{3}\right)$ for TVOC, VOCs, and VVOCs selected in this study in the test chamber for the twelve products tested.

\begin{tabular}{|c|c|c|c|c|c|c|c|c|c|c|c|c|c|}
\hline & CAS & $\begin{array}{c}\text { Inc } \\
1\end{array}$ & $\begin{array}{c}\text { Inc } \\
2\end{array}$ & $\begin{array}{c}\text { Inc } \\
3\end{array}$ & $\begin{array}{c}\text { Inc } \\
4\end{array}$ & $\begin{array}{c}\text { Inc } \\
5\end{array}$ & $\begin{array}{c}\text { Inc } \\
6\end{array}$ & $\begin{array}{c}\text { Inc } \\
7\end{array}$ & $\begin{array}{c}\text { Inc } \\
8\end{array}$ & $\begin{array}{c}\text { Inc } \\
9\end{array}$ & $\begin{array}{c}\text { Inc } \\
10\end{array}$ & $\begin{array}{c}\text { Inc } \\
11\end{array}$ & $\begin{array}{c}\text { Inc } \\
12\end{array}$ \\
\hline furan & $110-00-9$ & 6.9 & 1.8 & 1.4 & 2.0 & 0.6 & 3.1 & 1.8 & 4.5 & 6.8 & 4.2 & 5.4 & 6.0 \\
\hline isoprene & $78-79-5$ & 3.0 & 0.7 & 2.7 & 0.8 & 0.0 & 1.4 & 0.8 & 2.3 & 0.9 & 3.4 & 5.9 & 2.8 \\
\hline (E)-2-butenal & $123-73-9$ & - & 0.1 & - & - & 0.1 & 0.1 & - & - & 0.1 & 0.1 & 0.1 & 0.1 \\
\hline benzene & $71-43-2$ & 14.5 & 2.2 & 2.5 & 1.2 & 0.5 & 1.5 & 0.6 & 3.1 & 1.9 & 6.6 & 2.1 & 3.7 \\
\hline toluene & $108-88-3$ & 3.9 & 0.8 & 2.6 & 0.8 & 0.4 & 0.9 & 0.5 & 1.7 & 0.9 & 1.7 & 2.5 & 1.0 \\
\hline furfural & 98-01-1 & 2.6 & 0.6 & 0.6 & 0.6 & 0.7 & 0.8 & 1.9 & 1.4 & 1.0 & 1.2 & 1.5 & 1.9 \\
\hline styrene & $100-42-5$ & 0.7 & 0.2 & 0.4 & 0.2 & 0.2 & 0.3 & 0.2 & 0.3 & 0.1 & 0.7 & 0.3 & 0.1 \\
\hline $\begin{array}{l}\text { 2-furyl methyl } \\
\text { ketone }\end{array}$ & $1192-62-7$ & 0.1 & - & - & - & - & - & 0.1 & 0.1 & - & - & - & 0.1 \\
\hline phenol & $108-95-2$ & 0.3 & - & 0.1 & - & 0.1 & 0.0 & - & 0.1 & - & - & - & 0.0 \\
\hline naphthalene & $91-20-3$ & - & - & - & - & - & - & - & - & $0.0(2)$ & $0.0(2)$ & $0.0(3)$ & - \\
\hline formaldehyde & $50-00-0$ & 6.5 & 3.8 & 2.9 & 4.9 & 1.8 & 3.0 & 4.9 & 5.1 & 4.0 & 4.2 & 2.1 & 5.8 \\
\hline acetaldehyde & 75-07-0 & 5.8 & 2.8 & 1.2 & 1.7 & 0.9 & 1.4 & 0.9 & 0.2 & 3.1 & 1.3 & 2.7 & 0.2 \\
\hline acrolein & $107-02-8$ & 2.5 & 1.5 & 1.0 & 1.5 & 0.4 & 1.0 & 0.7 & 1.3 & 1.1 & 1.3 & 1.0 & 0.5 \\
\hline TVOC & & 25.9 & 7.1 & 10.9 & 8.8 & 3.9 & 6.1 & 4.7 & 11.4 & 8.1 & 14.9 & 15.8 & 24.7 \\
\hline
\end{tabular}

\subsection{Carcinogenic Compounds}

The compounds recognized as carcinogenic are benzene, furan, isoprene, formaldehyde, and acetaldehyde. Naphthalene and furfural are suspected to be carcinogenic. Figure 1 presents the TWA values of these compounds observed in the study.

It can be observed that the exposure levels are worrying for benzene, especially for Inc 1 and Inc 10. Only Inc 5 and Inc 7 show values of benzene below $1 \mu \mathrm{g} / \mathrm{m}^{3}$. It should be highlighted that all the values are above the guideline limit value derived, assuming an excess lifetime risk of $1 / 1,000,000$ of $0.17 \mu \mathrm{g} / \mathrm{m}^{3}$ [1]. Formaldehyde also presents high values being the worst cases for Inc 1 and Inc 12 but closely followed by Inc 4 , Inc 7 , and Inc 8 . However, the TWA values are below the guideline limit value of $100 \mu \mathrm{g} / \mathrm{m}^{3}$ [1] Though, considering that the limit value established by the WHO is based on $30 \mathrm{~min}$ of exposure, the comparison should be performed with STPC values (see Table 5). In that case, only Inc 5 and Inc 11 are below the guideline value. Inc 1 also presents the higher values for furan and acetaldehyde, followed by Inc 9 and Inc 11. Isoprene was detected at a higher concentration in Inc 11, followed by Inc 10, Inc 1, Inc 12, and Inc 3 . Concerning 
furfural, the higher emissions were detected again for Inc 1, followed by Inc 12 and Inc 7. Naphthalene was below the limit of detection in four incenses (Inc 1, Inc 2, Inc 5, and Inc 12), and values were relatively low in the other products, conducting to TWA values below $0.03 \mu \mathrm{g} / \mathrm{m}^{3}$, being therefore below the guideline value of $10 \mu \mathrm{g} / \mathrm{m}^{3}$. However, this is the value determined in the gaseous phase, and, probably, naphthalene would be detected in the particulate phase in higher concentrations. Overall, Inc 5 is the product with lower values of TWA for carcinogenic compounds.

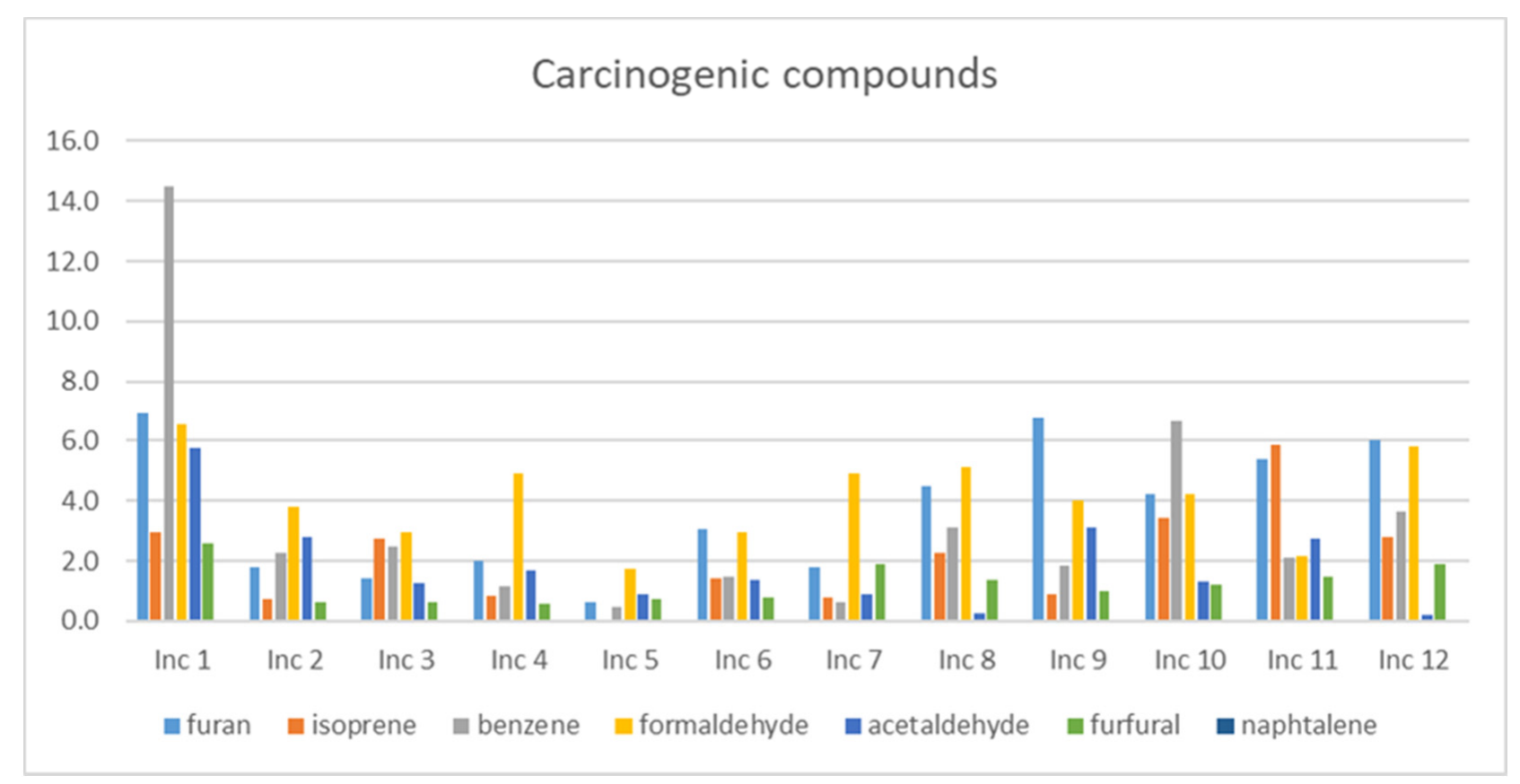

Figure 1. TWA levels $\left(\mu \mathrm{g} / \mathrm{m}^{3}\right)$ of the carcinogenic and suspected to be carcinogenic compounds in the twelve products studied.

\subsection{Mutagenic Compounds}

From the compounds detected, the only one recognized as mutagenic is benzene. Suspected to be mutagenic are furan, isoprene, formaldehyde, acetaldehyde, 2-butenal, and phenol. Figure 2 (on a different scale) presents the TWA values of these compounds observed in the study.

The data analysis, in this case, is similar to the previously done for carcinogenic compounds as some of them are the same. Benzene is again the most worrying compound, followed by formaldehyde. (E)-2-butenal was detected in seven products: Inc 2, Inc 5, Inc 6 , Inc 9, Inc 10, Inc 11 and Inc 12. Phenol was also detected in seven products: Inc 1, Inc 3, Inc 5 , Inc 6 , Inc 8 , Inc 9 and 12 . The values are low concerning long-term exposure, but they contribute to the overall exposure.

\subsection{Reprotoxic Compounds}

The compounds recognized as reprotoxic are toluene and styrene. Figure 3 presents the TWA values of these compounds observed in the study. 


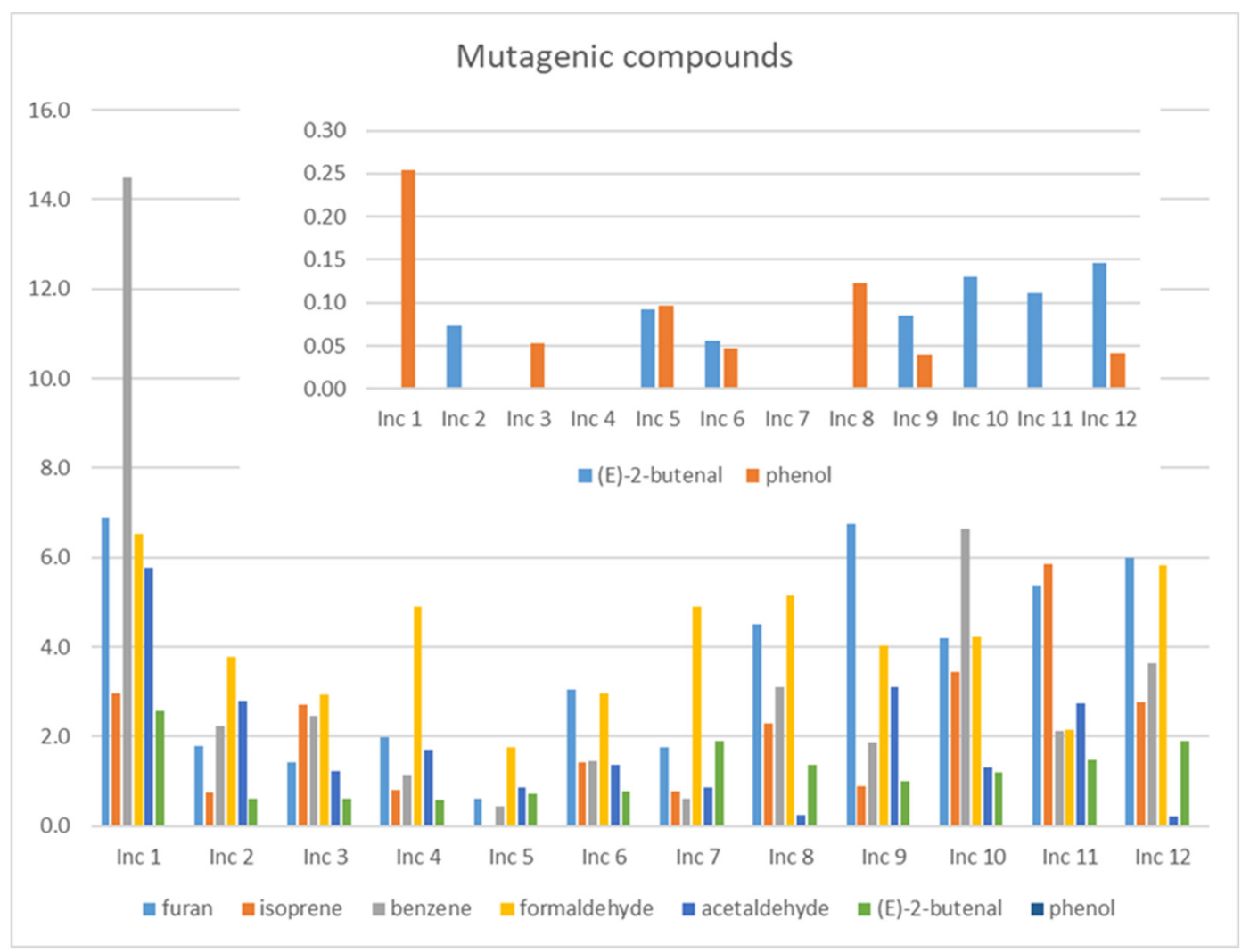

Figure 2. TWA levels $\left(\mu \mathrm{g} / \mathrm{m}^{3}\right)$ of the mutagenic and suspected to be mutagenic compounds in the twelve products studied.

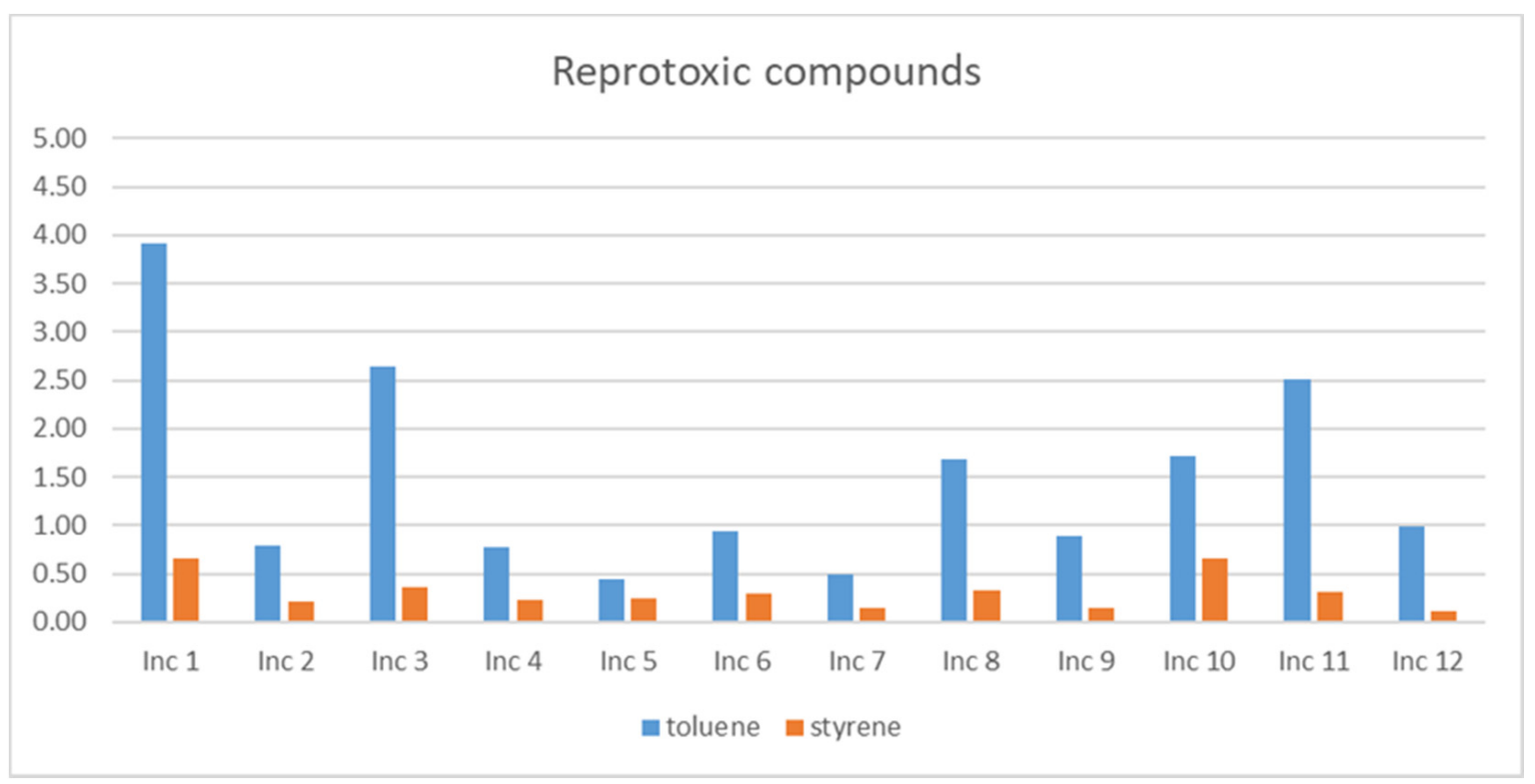

Figure 3. TWA levels $\left(\mu \mathrm{g} / \mathrm{m}^{3}\right)$ of the reprotoxic compounds in the twelve products studied.

Both compounds were detected in all products, being Inc 1 the incense with higher levels, followed by Inc 3 and Inc 11. Inc 5 and Inc 7 presented the lower concentration values. Both compounds present concentration levels below the guideline limit values established by the WHO. 


\subsection{Other Dangerous Compounds}

In this group, acrolein (fatal if swallowed, fatal if inhaled) and 2-furyl methyl ketone (fatal if inhaled, fatal in contact with skin) were identified. Given the acute effect, the values under analysis are the short-term peak concentration (STPC), presented in Figure 4.

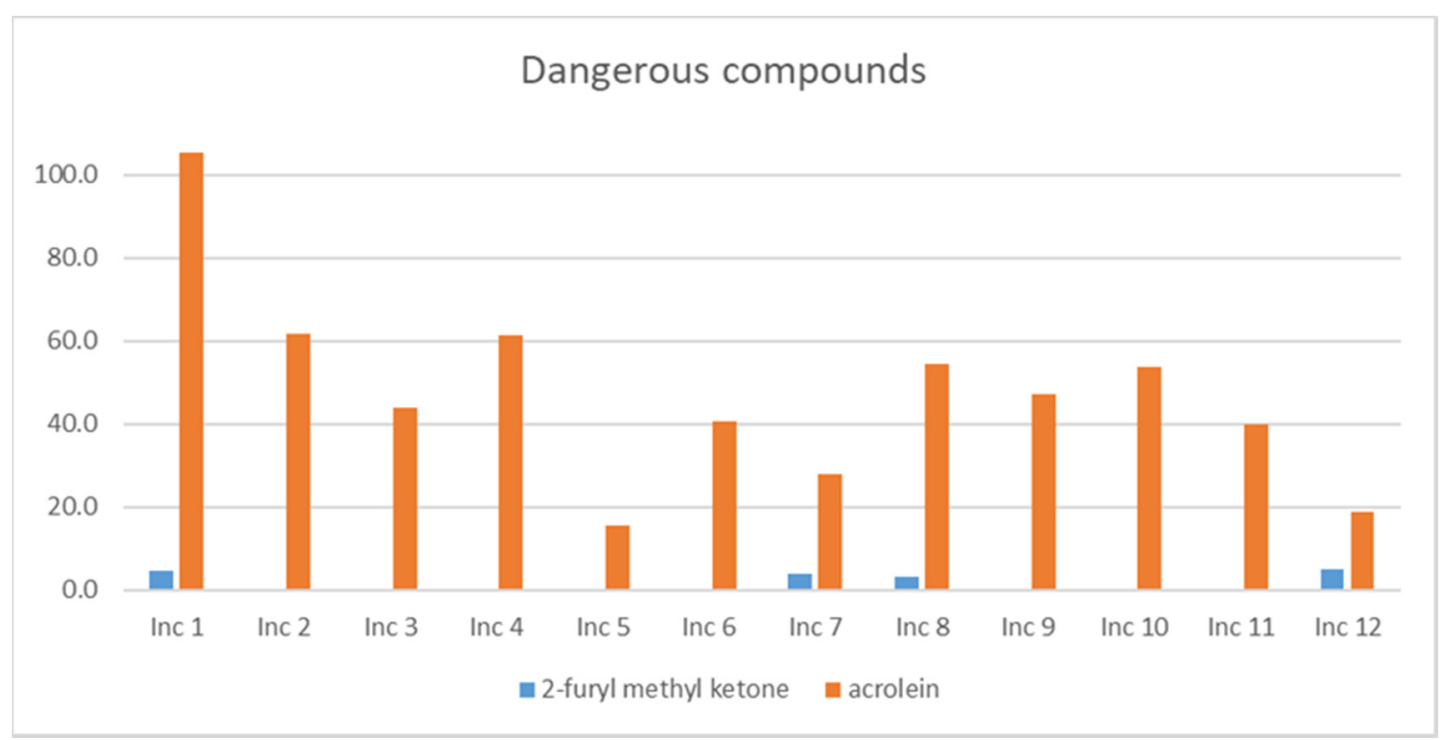

Figure 4. STPC concentrations $\left(\mu \mathrm{g} / \mathrm{m}^{3}\right)$ for other dangerous (fatal) compounds in the twelve products studied.

Acrolein was detected in all products, being Inc 1, the product with the higher value, and Inc 5, the product with the lower value. 2-furyl methyl ketone was detected in four products, although in low concentrations.

\subsection{TVOC Emissions}

TVOC emissions include all compounds eluted between hexane and hexadecane. Compounds like furan, isoprene, formaldehyde, acetaldehyde, and acrolein are excluded.

From the analysis of the results presented in Figure 5, it can be observed that Incense 1 and 12 have the highest emissions of TVOC, followed by incenses 10 and 11 . Note that these products $(1,11$, and 12) are cone type. The lowest values were observed for Inc 5 and Inc 7.

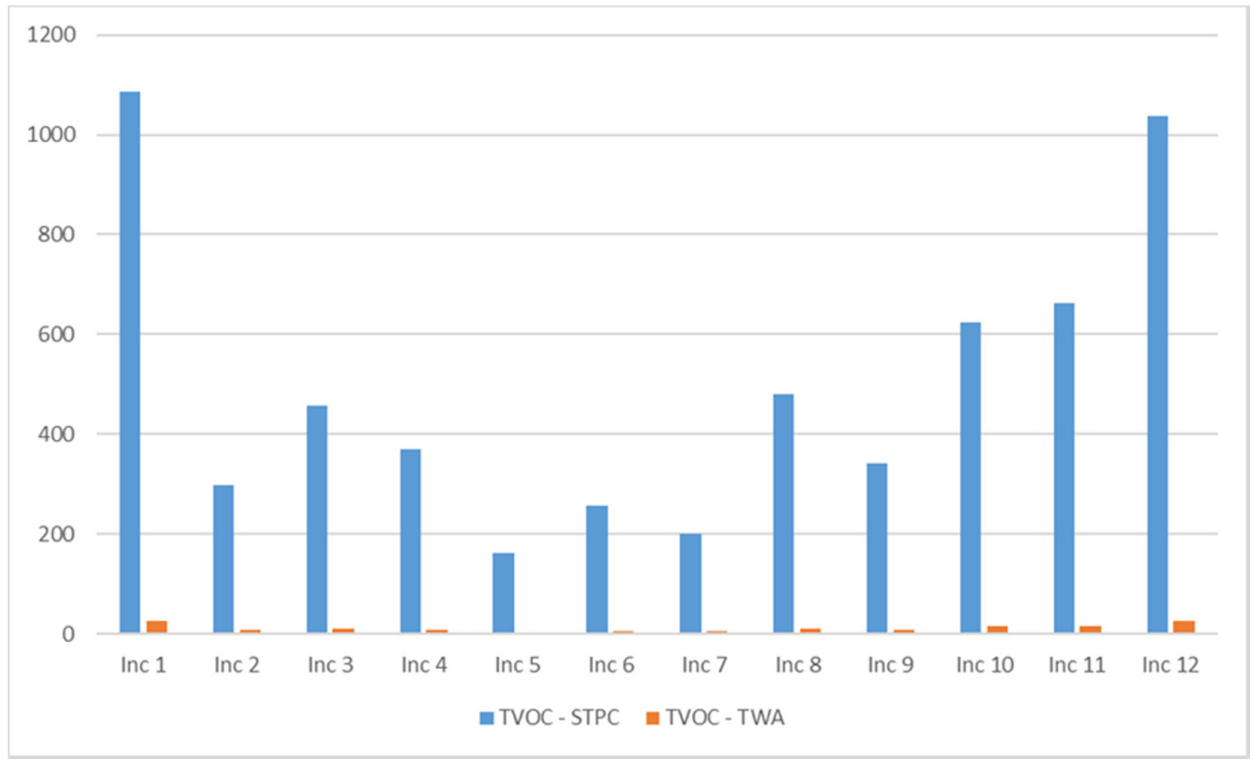

Figure 5. TVOC levels $\left(\mu \mathrm{g} / \mathrm{m}^{3}\right)$ in the twelve products studied. 


\section{Discussion}

\subsection{Influence of the Type of Incense}

It can be observed that incense 1 (cone type) presented high values for all the compounds, except for isoprene. After, the products with the worst performance were Incense 10,11 , and 12, although not for all compounds. The product with the best performance was Incense 5 (stick type). It should be noted that Incenses 1, 11, and 12 were cone type, which indicates that this type of incense is more pollutant than stick products. However, incense 10 (stick type) is the exception. From the present study, it can be concluded that incense cone type shows a great probability to be more pollutant than incense stick type.

\subsection{Influence of the Size of Incense}

The size of the incense, and its mass or volume, can also influence the level of pollution generated, as the time of burning is generally proportional to the size. In the family of stick products, it can be observed that Incense 5 presents the best performance and is the smaller one in terms of mass and volume. The largest stick product in terms of mass and volume is incense 8 , but it is the second-worst product, being incense 10 the worst. Therefore, the size of the incense influences the emissions level, but this is not linear. Concerning cone type, it can be observed that Incense 1 presents the worst performance, but it is smaller in terms of mass and volume, which shows that in this case, the composition of the product is much more relevant to the nature of the emissions.

However, it should be taken into account that normally, the persons left the products burning until the end of their life, and in this study, the burning time was limited to a maximum of $25 \mathrm{~min}$, for comparison purposes. Therefore, the bigger products, as they have a longer burning time, have more potential for pollution.

\subsection{Safety on Use Incenses: Assessment of the Risk}

Considering the compounds with guideline values, an assessment of the risk can be performed for the incense products and an analysis of the factors involved in the exposition.

Table 7 presents the values of STPC and TWA concentrations and the guideline values for those compounds.

Table 7. Average values of STPC (short-term peak concentration) $\left(\mu \mathrm{g} / \mathrm{m}^{3}\right)$ and TWA (worst-case time-weighted average) $\left(\mu \mathrm{g} / \mathrm{m}^{3}\right)$ of VOCs with guideline values for the twelve products tested.

\begin{tabular}{|c|c|c|c|c|c|c|c|c|c|c|c|c|c|}
\hline$S T P C\left(\mu \mathrm{g} / \mathrm{m}^{3}\right)$ & $\begin{array}{l}\text { Guideline Value } \\
\qquad\left(\mu \mathrm{g} / \mathrm{m}^{3}\right)\end{array}$ & $\begin{array}{c}\text { Inc } \\
1\end{array}$ & $\begin{array}{c}\text { Inc } \\
2\end{array}$ & $\begin{array}{c}\text { Inc } \\
3\end{array}$ & $\begin{array}{c}\text { Inc } \\
4\end{array}$ & $\begin{array}{c}\text { Inc } \\
5\end{array}$ & $\begin{array}{c}\text { Inc } \\
6\end{array}$ & $\begin{array}{c}\text { Inc } \\
7\end{array}$ & $\begin{array}{c}\text { Inc } \\
8\end{array}$ & $\begin{array}{c}\text { Inc } \\
9\end{array}$ & $\begin{array}{l}\text { Inc } \\
10\end{array}$ & $\begin{array}{c}\text { Inc } \\
11\end{array}$ & $\begin{array}{l}\text { Inc } \\
12\end{array}$ \\
\hline benzene & 0.17 & 608 & 94.2 & 103 & 48.4 & 18.9 & 61.1 & 25.1 & 131 & 78.0 & 279 & 89.4 & 153 \\
\hline toluene & 260 & 164 & 33.0 & 111 & 32.4 & 18.7 & 39.3 & 20.8 & 70.8 & 37.6 & 72.1 & 106 & 41.8 \\
\hline styrene & 260 & 27.6 & 9.04 & 15.2 & 9.70 & 10.1 & 12.5 & 6.38 & 13.6 & 5.98 & 27.8 & 13.0 & 4.41 \\
\hline naphthalene & 10 & & & & & & & & & 0.70 & 0.65 & 1.07 & \\
\hline formaldehyde & 100 & 274 & 159 & 123 & 206 & 73.9 & 125 & 206 & 216 & 169 & 177 & 90.0 & 244 \\
\hline$T W A\left(\mu \mathrm{g} / \mathrm{m}^{3}\right)$ & $\begin{array}{l}\text { Guideline value } \\
\left(\mu \mathrm{g} / \mathrm{m}^{3}\right)\end{array}$ & & & & & & & & & & & & \\
\hline benzene & 0.17 & 14.5 & 2.2 & 2.5 & 1.2 & 0.5 & 1.5 & 0.6 & 3.1 & 1.9 & 6.6 & 2.1 & 3.7 \\
\hline toluene & 260 & 3.9 & 0.8 & 2.6 & 0.8 & 0.4 & 0.9 & 0.5 & 1.7 & 0.9 & 1.7 & 2.5 & 1.0 \\
\hline styrene & 260 & 0.7 & 0.2 & 0.4 & 0.2 & 0.2 & 0.3 & 0.2 & 0.3 & 0.1 & 0.7 & 0.3 & 0.1 \\
\hline naphthalene & 10 & & & & & & & & & & & & \\
\hline formaldehyde & 100 & 6.5 & 3.8 & 2.9 & 4.9 & 1.8 & 3.0 & 4.9 & 5.1 & 4.0 & 4.2 & 2.1 & 5.8 \\
\hline
\end{tabular}


Considering short-term peak concentration, it can be observed that the values for benzene are higher than the guideline value between 100 times (Inc 5) and 3600 times (Inc 1). This represents a higher lifetime risk for cancer. Values obtained for formaldehyde are also higher than the guideline value, except in the case of Inc 5 and Inc 11. The values are higher than guideline values between 1.2 times and 2.7 times (Inc 1). The other compounds were all below guideline values.

Considering the worst-case time-weighted average, it can be observed that the values for benzene are higher than the guideline value between 3 times (Inc 5) and 85 times (Inc 1). The other compounds were all below guideline values.

From these facts, it could be said that Inc 5 seems to be the least bad and Inc 1 the worst, as it represents a higher risk of exposure to carcinogenic compounds.

The short-term peak concentration was calculated using the scenario of a room with a volume of $30 \mathrm{~m}^{3}$ and a ventilation rate of $0.5 \mathrm{~h}^{-1}$. On the other hand, the worst-case time-weighted average was calculated assuming the frequency of use 4 days per week and exposure time $1 \mathrm{~h}$ per day. If the ventilation rate is increased, the concentration levels will decrease, as we can see in Figure 6 for formaldehyde. Figure 7 shows the predictable behavior of the concentration with the variation of ventilation rate for Inc 1 and Inc 2. Based on the mathematical functions that best fit those points, it is possible to calculate the ventilation rate necessary to decrease the levels of formaldehyde to acceptable levels. For example, for Inc 1 only with a ventilation rate of $1.37 \mathrm{~h}^{-1}$ it will achieve a concentration of $100 \mu \mathrm{g} / \mathrm{m}^{3}$. However, it should be stressed that people can also be exposed to formaldehyde from multiple sources. Many building products emit formaldehyde, increasing the consumer's total exposure and overall risk. Therefore, using the precaution principle, the limit value for each product should be only a fraction of the guideline value for total exposure.

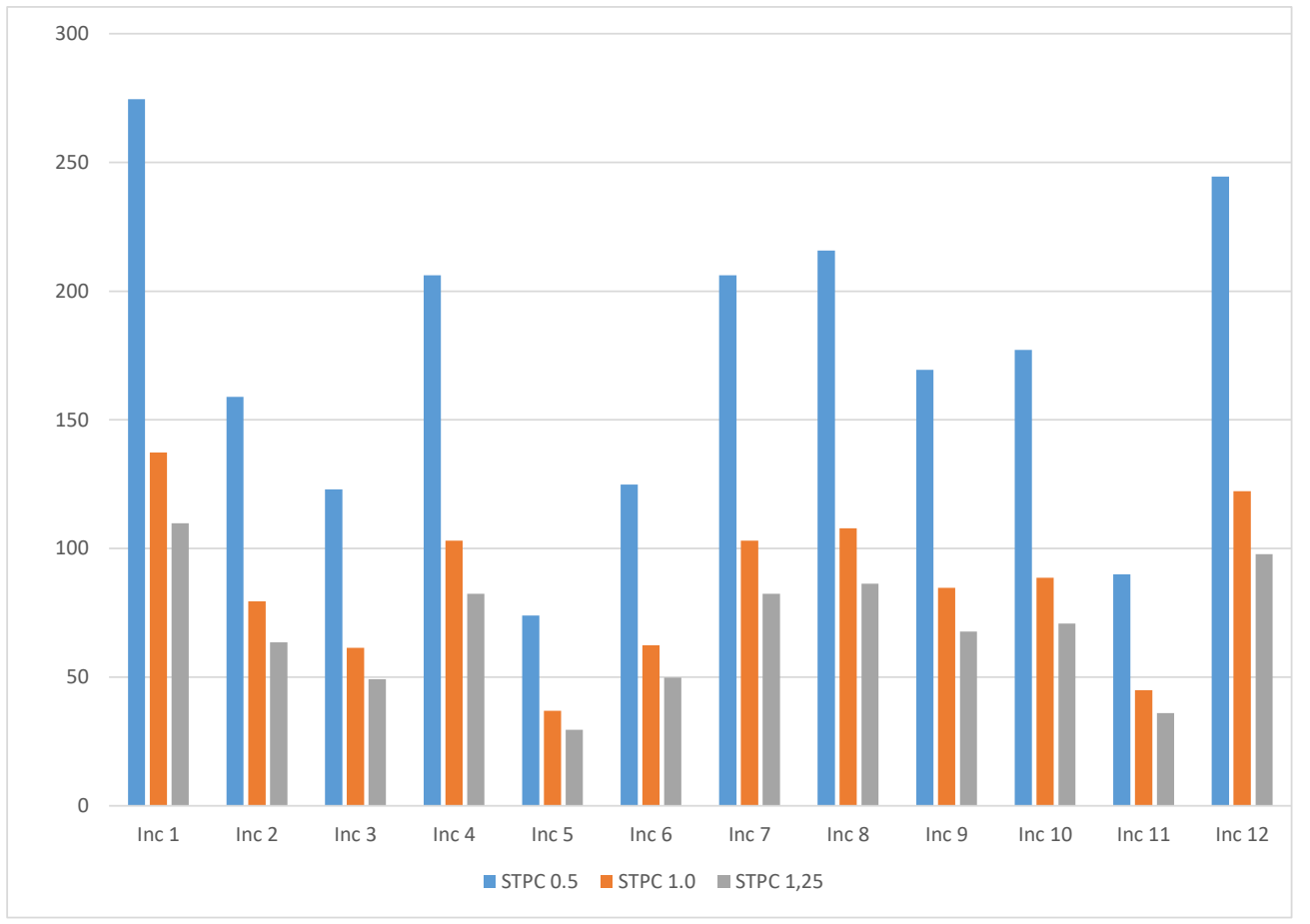

Figure 6. Average values of STPC (short-term peak concentration) $\left(\mu \mathrm{g} / \mathrm{m}^{3}\right)$ for formaldehyde assuming scenarios with different ventilation rates: $0.5 \mathrm{~h}^{-1}, 1.0 \mathrm{~h}^{-1}$, and $1.25 \mathrm{~h}^{-1}$. 


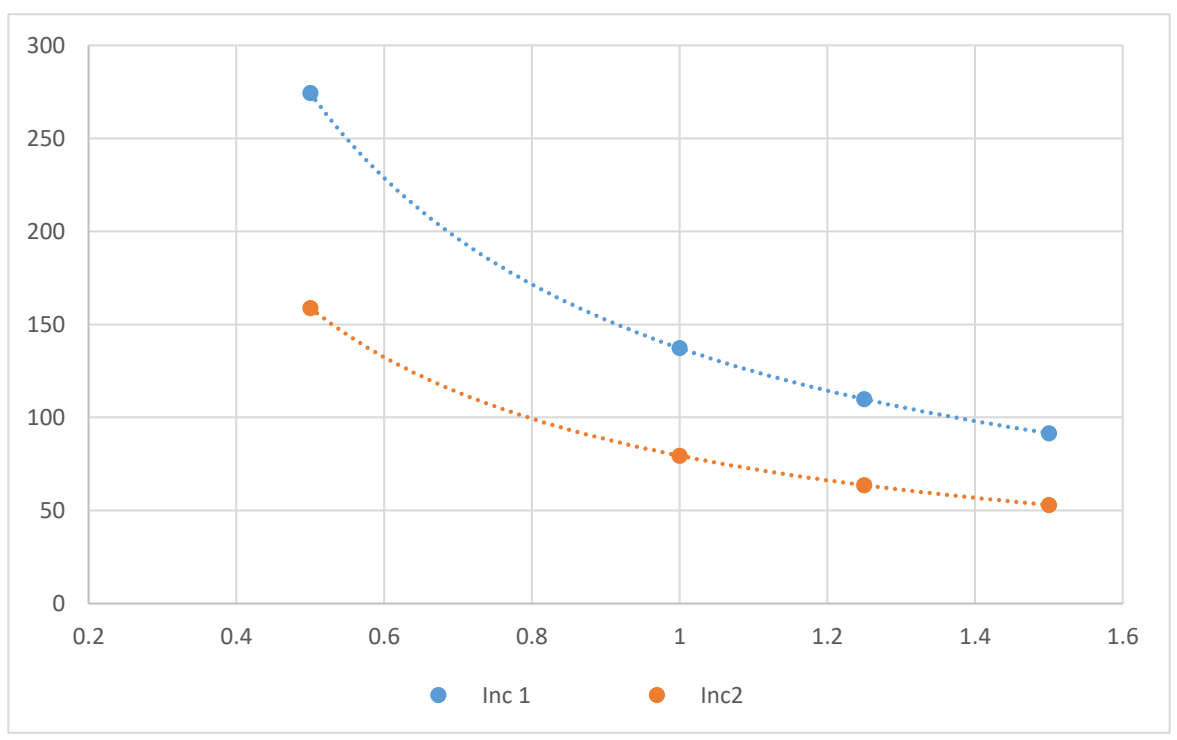

Figure 7. Better fit mathematical functions for values of STPC (short-term peak concentration) $\left(\mu \mathrm{g} / \mathrm{m}^{3}\right)$ for formaldehyde at different ventilation rates $\left(\mathrm{h}^{-1}\right)$ for Inc 1 and Inc 2.

\subsection{Recommendations for Users}

The results obtained show that some of the products tested can represent a risk to health in terms of inhalation exposure. Then some considerations are made about what the consumer can do to minimize the exposure resulting from incense products and consumer products in general.

There are two main strategies for risk reduction, "source control", where the nature or strength of the sources or even their existence indoors is removed, replaced, or moderated, and "exposure control", essentially through ventilation. The first strategy is preferable as prevention is better than mitigation. This option is, however, in the hands of the manufacturers and policy makers who can force to decrease the contaminants present in incense products. Another way of controlling exposure is the restriction of the time spent in a particular contaminated space and, as the last solution, dilution with increased ventilation, which can be implemented by the consumer.

First of all, the consumer should act responsibly and comply with the instructions of the product labels. He must be aware that some factors of their personnel activity in using a product have consequences on the concentration to which he is exposed, but also his family, including children. The manufacturer should provide this information in the instructions for use.

The frequency of use of incense and the duration of use will have a consequence on pollutant concentration which has a direct impact on the exposure to the pollutant. The greater these factors are, the higher the risk. The consumer should reduce the burning time and use it as few times as possible.

The quantity of products used will have a direct consequence on the concentration of pollutants which has a direct impact on exposure to the pollutant. Increasing the amount would increase the risk.

It should be stressed that people can be exposed to the same chemical from multiple sources. Many of the substances are also found in a wide range of other products, increasing the consumer's total exposures and overall risk.

Increasing the ventilation of a space is a fast way to dilute the concentration of a contaminant in the area where a product was used, assuming that the outdoor air is cleaner and will not increase the concentration of pollutants indoors. Increasing ventilation by opening the windows during and after burning incense will have a direct consequence on contaminant concentration, decreasing it, and would reduce the risk. 
In the case of extreme conditions, as high temperatures, high levels of ozone, and high levels of particulate matter, special attention should be taken to the use of incense products. Those extreme conditions could potentiate higher levels of exposure, for example, to secondary pollutants resultant from chemical reactions that will not occur in normal situations.

The consumer should diminish the time spent in the space where the incense was burned to decrease the time exposure. If possible, children should be absent from those spaces.

Special attention should be paid to vulnerable people such as children and people with health problems (asthma, COPD, etc). The inhalation rates of children are of major importance. Because of their size, physiology, behavior, and activity level, inhalation rates of children differ from those of adults. Potential determinants of children's susceptibility include the continuing process of lung growth and development, incomplete metabolic system, immature host defenses, high rates of infection with respiratory pathogens [31].

\section{Conclusions}

This study has shown that incense products are relevant sources of indoor pollution in terms of gaseous pollutants, and in particular of dangerous substances. The study also indicated that incense cone type shows a great probability to be more pollutant than incense stick type, as from the 12 products tested, three of the four higher polluters were of the cone type.

Benzene and formaldehyde present worrying levels in the major part of the products, above guideline values established by the WHO (2010) [1]. Unfortunately, no limit values are established for indoor air for all the compounds studied, but this fact should not exempt us from taking action to alert the population to the potential danger of using those products. From this study, acetaldehyde, acrolein, furfural, and furan emerge as compounds with levels to deserve attention.

Many dangerous compounds are controlled, as they are not reported often, and the establishment of guidelines is focused on compounds usually found in indoor air. This methodology can create a vicious circle, as the new studies tend to focus on compounds with guidelines established, and other compounds tend to be neglected. We expect to contribute with data on concerning compounds despite having been outside the concern of the legislators.

Author Contributions: Conceptualization, G.V.S.; methodology, G.V.S., A.O.M. and S.D.S.M.; formal analysis, G.V.S., A.O.M. and S.D.S.M.; data curation, G.V.S.; writing-original draft preparation, G.V.S.; writing-review and editing, A.O.M.; supervision, G.V.S. All authors have read and agreed to the published version of the manuscript.

Funding: This research received no external funding.

Institutional Review Board Statement: Not applicable.

Informed Consent Statement: Not applicable.

Data Availability Statement: Data is contained within the article.

Conflicts of Interest: The authors declare no conflict of interest.

\section{References}

1. World Health Organization. WHO Guidelines for Indoor Air Quality: Selected Pollutants; WHO Press, WHO Regional Office for Europe: Copenhagen, Denmark, 2010. Available online: https://www.euro.who.int/en/health-topics/environment-and-health/ air-quality/publications/2010/who-guidelines-for-indoor-air-quality-selected-pollutants (accessed on 3 May 2021).

2. Uhde, E.; Salthammer, T. Impact of reaction products from building materials and furnishings on indoor air quality-A review of recent advances in indoor chemistry. Atmos. Environ. 2007, 41, 3111-3128. [CrossRef]

3. Missia, D.A.; Demetriou, E.; Michael, N.; Tolis, E.I.; Bartzis, J.G. Indoor exposure from building materials: A field study. Atmos. Environ. 2010, 44, 4388-4395. [CrossRef] 
4. Capíková, A.; Tesařová, D.; Hlavaty, J.; Ekielski, A.; Mishra, P.K. Estimation of Volatile Organic Compounds (VOCs) and Human Health Risk Assessment of Simulated Indoor Environment Consisting of Upholstered Furniture Made of Commercially Available Foams. Adv. Polym. Technol. 2019, 2019, 1-10. [CrossRef]

5. Nazaroff, W.W.; Weschler, C.J. Cleaning products and air fresheners: Exposure to primary and secondary air pollutants. Atmos. Environ. 2004, 38, 2841-2865. [CrossRef]

6. Bartzis, J.; Wolkoff, P.; Stranger, M.; Efthimiou, G.; Tolis, E.I.; Maes, F.; Nørgaard, A.W.; Ventura, G.; Kalimeri, K.K.; Goelen, E.; et al. On organic emissions testing from indoor consumer products' use. J. Hazard. Mater. 2015, 285, 37-45. [CrossRef]

7. Lin, C.-C.; Chen, H.-Y. Impact of HVAC filter on indoor air quality in terms of ozone removal and carbonyls generation. Atmos. Environ. 2014, 89, 29-34. [CrossRef]

8. Kagi, N.; Fujii, S.; Horiba, Y.; Namiki, N.; Otani, Y.; Emi, H.; Tamura, H.; Kim, Y.S. Indoor air quality for chemical and ultrafine particle contaminants from printers. Build. Environ. 2007, 42, 1949-1954. [CrossRef]

9. He, C.; Morawska, L.; Hitchins, J.; Gilbert, D. Contribution from indoor sources to particle number and mass concentrations in residential houses. Atmos. Environ. 2004, 38, 3405-3415. [CrossRef]

10. Cacho, C.; Ventura, G.; Martins, A.; Oliveira Fernandes, E.; Saraga, D.; Dimitroulopoulou, C.; Bartzis, J.G.; Rembges, D.; Barrero, J.; Kotzias, D. Air pollutants in office environments and emissions from electronic equipment: A review. Fresenius Environ. Bull. 2013, 22, 2488-2497.

11. Kuo, S.-C.; Tsai, Y.I.; Sopajaree, K. Emission identification and health risk potential of allergy-causing fragrant substances in PM2.5 from incense burning. Build. Environ. 2015, 87, 23-33. [CrossRef]

12. Jetter, J.J.; Guo, Z.; McBrian, J.A.; Flynn, M.R. Characterization of emissions from burning incense. Sci. Total Environ. 2002, 295, 51-67. [CrossRef]

13. Lee, S.-C.; Wang, B. Characteristics of emissions of air pollutants from burning of incense in a large environmental chamber. Atmos. Environ. 2004, 38, 941-951. [CrossRef]

14. Kuo, S.-C.; Tsai, Y.I.; Sopajaree, K. Emission characteristics of carboxylates in PM2.5 from incense burning with the effect of light on acetate. Atmos. Environ. 2016, 138, 125-134. [CrossRef]

15. Bootdee, S.; Chantara, S.; Prapamontol, T. Determination of PM2.5 and polycyclic aromatic hydrocarbons from incense burning emission at shrine for health risk assessment. Atmos. Pollut. Res. 2016, 7, 680-689. [CrossRef]

16. Lui, K.; Bandowe, B.A.M.; Ho, S.S.H.; Chuang, H.-C.; Cao, J.-J.; Chuang, K.-J.; Lee, S.-C.; Hu, D.; Ho, K. Characterization of chemical components and bioreactivity of fine particulate matter (PM2.5) during incense burning. Environ. Pollut. 2016, 213, 524-532. [CrossRef] [PubMed]

17. Kuo, S.-C.; Tsai, Y.I. Emission characteristics of allergenic terpenols in PM2.5 released from incense burning and the effect of light on the emissions. Sci. Total Environ. 2017, 584-585, 495-504. [CrossRef]

18. Ho, S.S.H.; Yu, J.Z. Concentrations of formaldehyde and other carbonyls in environments affected by incense burning. J. Environ. Monit. 2002, 4, 728-733. [CrossRef]

19. Lin, T.-C.; Krishnaswamy, G.; Chi, D.S. Incense smoke: Clinical, structural and molecular effects on airway disease. Clin. Mol. Allergy 2008, 6, 3. [CrossRef]

20. He, J.-R.; Wei, D.-M.; Chan, F.-F.; Luan, Y.-Z.; Tu, S.; Lu, J.-H.; Li, W.-D.; Yuan, M.-Y.; Chen, N.-N.; Chen, Q.-Z.; et al. Associations between maternal exposure to incense burning and blood pressure during pregnancy. Sci. Total Environ. 2018, 610-611, 1421-1427. [CrossRef]

21. Wei, C.-F.; Chen, M.-H.; Lin, C.-C.; Guo, Y.L.; Lin, S.-J.; Hsieh, W.-S.; Chen, P.-C. Household incense burning and infant gross motor development: Results from the Taiwan Birth Cohort Study. Environ. Int. 2018, 115, 110-116. [CrossRef]

22. Lu, F.; Li, S.; Shen, B.; Zhang, J.; Liu, L.; Shen, X.; Zhao, R. The emission characteristic of VOCs and the toxicity of BTEX from different mosquito-repellent incenses. J. Hazard. Mater. 2020, 384, 121428. [CrossRef] [PubMed]

23. Wang, L.; Zheng, X.; Stevanovic, S.; Xiang, Z.; Liu, J.; Shi, H.; Yu, M.; Zhu, C. Characterizing pollutant emissions from mosquito repellents incenses and implications in risk assessment of human health. Chemosphere 2018, 191, 962-970. [CrossRef] [PubMed]

24. ECHA-European Chemicals Agency. Available online: https:/ / echa.europa.eu/home (accessed on 15 January 2021).

25. ISO 16000-9. Determination of the Emission of Volatile Organic Compounds from Building Products and FurnishingEmission Test Chamber Method. 2006. Available online: https://www.iso.org/obp/ui/\#iso:std:iso:16000:-9:ed-1:v2:en (accessed on 3 May 2021).

26. EN 16738. Emission Safety of Combustible Air Fresheners-Test Methods. 2015. Available online: https://standards.iteh.ai/ catalog/standards/cen/7504b3f2-ff64-4673-b5c9-1d0a38d30ef6/en-16738-2015 (accessed on 3 May 2021).

27. ISO 16000-6. Determination of Volatile Organic Compounds in Indoor and Test Chamber Air by Active Sampling on Tenax TA Sorbent, Thermal Desorption and Gas Chromatography Using MS/FID. 2011. Available online: https://www.iso.org/standard/ 52213.html (accessed on 3 May 2021).

28. ISO 16000-3. Determination of Formaldehyde and Other Carbonyl Compounds-Active Sampling Method. 2011. Available online: https: / / www.iso.org/standard/51812.html (accessed on 3 May 2021).

29. EN 16739. Emission Safety of Combustible Air Fresheners-Methodology for the Assessment of Test Results and Application of Recommended Emission Limits. 2015. Available online: https://shop.bsigroup.com/ProductDetail?pid=000000000030298793 (accessed on 3 May 2021). 
30. Air Quality Guidelines for Europe, 2nd ed.; WHO Regional Publications, European Series, No. 91; WHO Regional Office for Europe: Copenhagen, Denmark, 2000. Available online: https://www.euro.who.int/en/publications/abstracts/air-quality-guidelinesfor-europe (accessed on 3 May 2021).

31. World Health Organization. Regional Office for Europe \& European Centre for Environment and Health. Effects of Air Pollution on Children's Health and Development: A Review of the Evidence; WHO Regional Office for Europe: Copenhagen, Denmark, 2005; Available online: https:/ /apps.who.int/iris/handle/10665/107652 (accessed on 3 May 2021). 